RECENT ADVANCES

\title{
Should recombinant human growth hormone therapy be used in short small for gestational age children?
}

\author{
L B Johnston, M O Savage
}

Arch Dis Child 2004;89:740-744. doi: 10.1136/adc.2003.034785

Short small for gestational age (SGA) children represent $20 \%$ of all children with short stature' and therefore constitute a significant portion of the caseload in a growth clinic. The recent approval of recombinant human growth hormone $(G H)$ for the treatment of short stature in SGA children by the European Union's Committee on Proprietary Medicinal Products offers a new licensed therapeutic option. This article examines the role of $\mathrm{GH}$ therapy in short SGA children with particular reference to selection of patients, effectiveness, safety, and its potential metabolic implications.

See end of article for authors' affiliations

Correspondence to: Dr L B Johnston, Senior Lecturer Honorary Consultant, Paediatric Endocrinology, St Bartholomew's Hospital London ECIA 7BE, UK; l.b.Johnston@qmul.ac.uk

Accepted 1 December 2003
$\mathrm{S}$ mall for gestational age (SGA) describes an infant's size at birth compared to appropriate population standards and is not synonymous with intrauterine growth retardation (IUGR). demonstrates subnormal prenatal growth velocity. Infants born following IUGR may or may not be SGA. The definition of SGA is arbitrary, but in growth clinics SGA is commonly defined as birth weight and/or length two or more standard deviation scores below the mean for gender and gestation (-2 SDS), which is consistent with the definition of childhood short stature (standing height $\leqslant-2$ SDS). As birth length is not always available in the UK and is often not as reliably measured as weight, SGA is most commonly defined by birth weight alone in the UK.

The aetiology of being SGA at birth is complex, involving the interplay of fetal, maternal, and placental environmental and genetic factors. ${ }^{2}{ }^{3}$ Although some SGA infants are dysmorphic, the majority are not and the cause in the individual patient is not always apparent. Thus SGA children form a heterogeneous group that may include some children with familial SGA. The cause of SGA should always be investigated, preferably shortly after birth, because a positive finding will increase the potential for counselling the parents regarding the likely prognosis and allow any appropriate specific therapies to be instigated. Causes such as preeclampsia, maternal smoking, or drug abuse may be apparent from the history, while other causes such as congenital infection or chromosomal abnormalities will require specific investigation.

\section{NATURAL GROWTH PATTERNS SEEN IN SGA INFANTS}

A Swedish cohort study of 3650 term singleton SGA infants showed that postnatal growth IUGR requires antenatal fetal auxology that acceleration, or catch-up growth, results in approximately $87 \%$ SGA children being within the normal population height standards ( \pm 2 SDS) by 2 years of age. ${ }^{1}$ The mean final height in the subjects with catch-up growth was -0.7 SDS compared with -1.7 SDS in those who had not caught up by 2 years. At 18 years of age, $7.9 \%$ of the subjects born SGA remained short; thus only a small minority (5\%) continued to catch up spontaneously during childhood. The best predictors of catch-up growth were longer birth length and taller midparental height.

A significant number of SGA infants are born prematurely; they have a different pattern of postnatal growth where catch-up growth occurs at a later age than term SGA infants ${ }^{45}$ (see table 1). In the Dutch study, shown in table 1, there was no significant difference in the proportion of term and preterm SGA children who had caught up at 2 years, but at 6 months and 1 year fewer premature SGA children had catch-up growth. Thus consideration of the gestational age of the SGA child at birth is important during any assessment of their early postnatal growth, to avoid wrongly assigning a premature infant, with delayed catch-up growth, to a non-catch-up group. It is therefore appropriate that the GH therapy licence for short SGA children recommends that treatment should not be commenced before the age of 4 years. In addition it is recommended that the height velocity SDS should be below zero to reduce the possibility of treating any SGA child with spontaneous catch-up growth.

\section{GH:INSULIN-LIKE GROWTH FACTOR I (IGF-I) AXIS STATUS IN SHORT SGA CHILDREN}

The pathophysiology of the poor postnatal growth in short SGA children is not fully understood and is likely to vary between individuals given the heterogeneity of the group.

GH levels are higher in the newborn period in SGA infants compared to controls, but by midchildhood the situation has changed. ${ }^{6}$ Spontaneous GH secretion studies and GH provocation tests have shown that up to half of short SGA children have subnormal peak GH $(<20 \mathrm{mU} / \mathrm{l})$ and/or low mean $\mathrm{GH}$ secretion rates compared to normal controls. ${ }^{78}$

In the newborn SGA infant, cord IGF-I, IGF-II, and insulin levels are lower than levels in appropriate for gestational age infants which

Abbreviations: $G H$, growth hormone; IGF, insulin-like growth factor; IUGR, intrauterine growth retardation; SGA, small for gestational age 
Table 1 Percentage of premature $(n=423)$ and term $(n=301)$ Dutch SGA children with catch-up growth at 6 months, and 1 and 2 years of age ${ }^{4}$

\begin{tabular}{llll}
\hline & At $\mathbf{6}$ months & At 1 year & At 2 years \\
\hline Premature SGA & $40 \%$ & $65 \%$ & $82.5 \%$ \\
Term SGA & $71 \%$ & $81 \%$ & $87.5 \%$ \\
\hline
\end{tabular}

may relate to placental insufficiency but, in the majority, this reverses within the first few days of life. ${ }^{6}$ In childhood, serum IGF-I levels may lie within the normal reference range, but the majority of short SGA children $(80 \%$ in a Swedish study) have IGF-I levels below the 50th centile, supporting the diagnosis of GH and/or IGF-I insufficiency. ${ }^{10}$

Subtle defects in the GH:IGF-I axis may therefore contribute to poor postnatal catch-up growth. This observation led to the first trials of GH therapy, with subsequent observation of growth acceleration, in short SGA children. ${ }^{11}$ However, the larger more recent trials do not report any significant difference in response between those with and without GH insufficiency. ${ }^{12}$ Therefore the evidence suggests that $\mathrm{GH}$ provocation or $\mathrm{GH}$ profile testing is not necessary before treatment with GH as the status of GH secretion is not going to change the decision to treat or the dose of $\mathrm{GH}$ recommended. However, IGF-I and IGFBP-3 should always be measured before the start of treatment (see below).

Recently endocrine studies comparing Italian children born SGA with and without catch-up have been reported. These studies found that the non catch-up SGA children tended to have higher TSH levels and higher cortisol levels. ${ }^{13}{ }^{14}$ Thus subtle defects of the thyroid axis or adrenal axis may also influence postnatal growth in SGA children.

\section{THE EFFECT OF GH THERAPY ON LINEAR GROWTH IN SHORT SGA CHILDREN}

The impact of GH therapy on linear growth in short SGA children has been the subject of a large number of published trials. Table 2 summarises the findings of some of the principal studies showing doses in comparable units.

Randomised control trials have proven that treated subjects have significant growth acceleration in childhood, maximal in the first year but continuing into the second and third years when compared to untreated or placebo treated short SGA controls. ${ }^{12} 1525$ There is some growth deceleration on discontinuing therapy but the majority of the height gain is retained. ${ }^{182226}$

The optimal dose is currently debated in Europe. The initial growth response is dose dependent with those on higher doses showing more rapid catch-up growth. ${ }^{12}{ }^{15}$ Proponents of the higher dose $(0.067 \mathrm{mg} / \mathrm{kg} /$ day $)$ claim the importance of rapid normalisation of height and the importance of dose in the growth prediction models justifies the higher IGF-I levels ( $30 \%$ of cases have IGF-I SDS $>2$ ) seen in these subjects (Professor Paul Czernichow, personal communication). However, the commonly used lower dose $(0.033 \mathrm{mg} / \mathrm{kg} /$ day), which is greater than the replacement dose for growth hormone deficiency $(0.025 \mathrm{mg} / \mathrm{kg} /$ day $)$, results in significant gains in linear growth, lower IGF-I levels, and a similar gain in final height to the higher dose at lower cost. ${ }^{16}$ Therefore the new licence has opted to recommend a dose of $0.035 \mathrm{mg} /$ $\mathrm{kg} / \mathrm{day}$.

The gain in final height is greater if the treatment is started at an earlier age. The Dutch SGA study treated children for six years from the mean age of around 7 years and documented a final height gain of 2.2 SDS (controls 0.3 SDS gain) compared to a French high dose treatment study where adolescent subjects were treated for a mean 2.7 years from a mean age of 12.7 and height gain was 1.1 SDS (controls 0.4 SDS gain). ${ }^{16}{ }^{23}$ Two further studies compared growth in GH insufficient short SGA children treated with lower doses of $\mathrm{GH}$, with growth in untreated non $\mathrm{GH}$ deficient short SGA children and found no significant gain in final height. ${ }^{24}{ }^{27}$ Commencing treatment around the time of puberty results in more modest height gain and higher GH doses may be required. Families should be warned of this.

In order to achieve maximum benefit continuous GH therapy is thus recommended from 4 years of age, which is supported by the recently published response prediction model, generated from $618 \mathrm{GH}$ treated short SGA subjects and validated in 68 independent patients. ${ }^{28}$ This model shows that $52 \%$ of the variability in the first year growth response can be attributed to the dose of GH given, the mid-parental height, and the weight and age at the start of treatment. The first three variables are positively correlated whereas age is negatively correlated. This prediction model could be used in the future to individualise therapy by refining the recommended GH dosage in individual patients.

Several studies have observed a deceleration of growth on stopping GH therapy which is less marked than the previous acceleration-that is, a net benefit may be achieved with short courses of therapy. One small study giving intermittent treatment with high doses of $\mathrm{GH}$ has shown treatment (alternating two years on and two years off) resulted in a height gain of 1.7 SDS after six years-that is, four treated and two untreated years. ${ }^{22}$ The new licence recommends continuous therapy but there may be significant benefits to the family and also potential cost reduction in discontinuous regimens. Such protocols require continuing research before they can be recommended and may only be appropriate in a child starting GH therapy at an early age.

Thus the goals of treatment, which are induction of catchup growth with normalisation of childhood height and growth, and increased final adult height can be achieved. Few adverse drug reactions have been reported which are related to the GH therapy itself. In addition the improvements in linear growth do not negatively influence body proportions or unduly accelerate skeletal maturation. ${ }^{12} 2629$ However, GH therapy also has some metabolic effects.

\section{EFFECTS OF GH THERAPY ON BODY COMPOSITION IN SHORT SGA CHILDREN}

The Dutch SGA study found that body mass index (BMI) in short SGA children was significantly reduced compared to controls $(-1.3$ SDS $){ }^{30}$ However, with GH treatment, BMI normalised over five years.

But what is the effect of GH therapy on body composition? Leger et al studied 14 short SGA children during three years of GH therapy and one year off therapy using magnetic resonance imaging of adipose tissue and muscle in the thigh. ${ }^{31}$ They found that during GH therapy short SGA subjects increased muscle and decreased adipose tissue cross sectional area. At the end of three years the SGA children had greater muscle surface area than controls but adipose tissue was similar. One year after stopping GH therapy there was maintenance of the muscle and adipose tissue suggesting these changes in body composition may be long lasting.

WHAT HAPPENS TO IGF-I LEVELS ON GH THERAPY? IGF-I levels, which are typically in the lower half of the normal range, increase on GH therapy. ${ }^{10}{ }^{12}$ In the Swedish SGA study IGF-I levels rose by $55 \%$ on day $10,90 \%$ after one year and by $123 \%$ at the end of two years GH treatment $(0.033 \mathrm{mg} / \mathrm{kg} / \mathrm{day})$. The increase was dose dependent, with higher doses stimulating greater increases in serum IGF-I. Increasing the levels of IGF-I is probably the major 


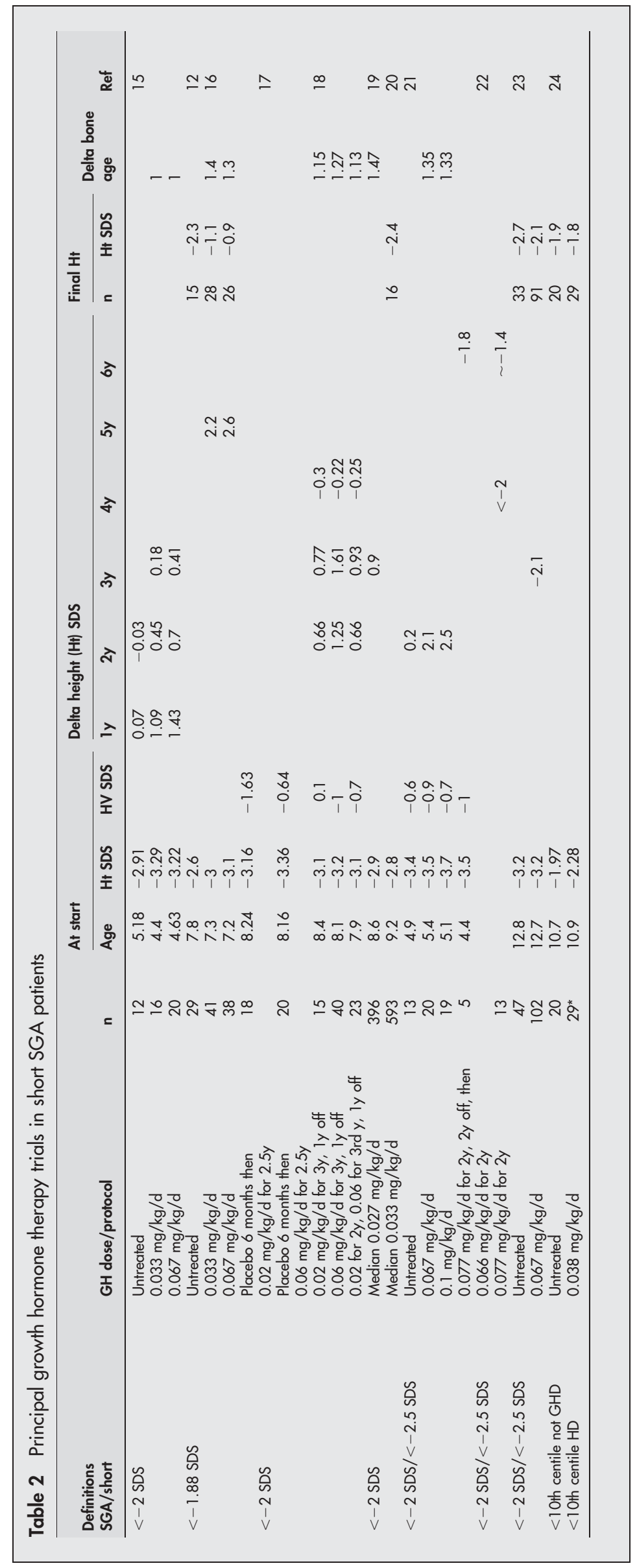




\section{Information box}

Indications for GH therapy in short SGA child

- Birth size $<-2$ SDS

- Height $<-2.5$ SDS ( $\geqslant 1$ SDS below target height)

- Age over 4 years

- Height velocity $<0$ SDS

Achievable goals of therapy

- Induce catch-up growth in childhood

- Normalise growth in childhood

- Improve adult height

Potential risks of therapy

- Supraphysiological circulating IGF-I

- Insulin resistance

Important aspects of therapy

- Should be initiated and monitored by a paediatric endocrinologist

- Before starting treatment

- Check IGF-I, IGF-BP3, fasting lipids, insulin, and glucose

- Measure BP

- On treatment

- Regular auxology to monitor linear growth response

- Monitor serum IGF-I, fasting insulin, and glucose

- Monitor BP

mechanism of inducing catch-up growth in short SGA subjects and clear correlation between rise in IGF-I and linear growth response has been reported. ${ }^{10}$ Indeed IGF-I response predicts $42 \%$ of the variance of the one year growth response in the Swedish study.

However, there is no evidence showing what other short or long term effects high IGF-I levels have in childhood. There are theoretical risks of acromegalic symptoms and complications, including cardiomyopathy and bowel pathology. ${ }^{32}$ It is therefore important not only to monitor growth response on GH therapy but also to monitor IGF-I at least annually and reduce the GH dose if IGF-I levels are more than two standard deviations above the normal reference range.

\section{WHAT ARE THE METABOLIC EFFECTS OF GH THERAPY IN SHORT SGA CHILDREN?}

Epidemiological studies have documented, initially in adult life but more recently also in children, that small birth size is associated with an increased risk of insulin resistance, type 2 diabetes, hypertension, hyperlipidaemia, and cardiovascular disease-all features of the metabolic syndrome. ${ }^{33-35}$

Systolic blood pressure in untreated short children born SGA was raised at baseline (0.7 SDS) but diastolic blood pressure was similar (-0.1 SDS). ${ }^{30}$ During five years of GH therapy, both the systolic and diastolic blood pressures fell to normal levels compared with control data. In the same group of patients, total cholesterol, LDL cholesterol, and the atherogenic index improved over five years although no change was noted in HDL cholesterol levels. On discontinuation of therapy this improvement in blood pressure and lipid profile was not lost over six months. ${ }^{36}$

Decreased insulin sensitivity (raised insulin levels following an oral glucose load compared to age matched controls) can already be documented in childhood and early adulthood in subjects born SGA. ${ }^{34}{ }^{35}$ Recently a study comparing SGA children with and without catch-up found higher fasting insulin levels and increased post-load insulin secretion in those who had caught up in terms of weight and linear growth compared to non-catch-up subjects and controls. ${ }^{37}$ This needs to be confirmed in other populations, but suggests that the short children who have not caught up may be at lower risk of this feature of the metabolic syndrome.

It has been confirmed that fasting glucose, insulin, and proinsulin levels rise and insulin sensitivity falls on GH therapy (44\% in 12 short SGA subjects with a mean age of 9.3 years). ${ }^{38} 39$ However these studies have different findings three months after GH therapy has been discontinued, with one showing significant improvement in insulin sensitivity and the other showing no improvement. Studies six months after stopping $\mathrm{GH}$ treatment have found that glucose and insulin levels on an oral glucose tolerance test are similar between controls and SGA children (mean age 16 years). ${ }^{36}$ Thus the adverse effects on insulin sensitivity would appear to be reversible.

In summary, there is a clearly documented increased risk of hypertension, insulin resistance, hyperlipidaemia, and cardiovascular disease in SGA subjects later in life. These risks appear to be greater in those that show catch-up, particularly where this is rapid or exaggerated..$^{37}$ Treatment with GH therapy in short SGA subjects would appear to improve blood pressure and lipid profiles but increase insulin resistance in the short term. Fortunately the insulin resistance appears to be reversible on discontinuing treatment. However, the long term effects are not known, so continued monitoring of variables of insulin sensitivity in these subjects is required into adulthood.

\section{OTHER INFLUENCES OF GH THERAPY IN SHORT SGA SUBJECTS}

Children born SGA may also have a small head circumference and learning difficulties. These features are predicted by the severity of SGA as opposed to just the presence of SGA. ${ }^{40}$ Short SGA children also have lower self-concept (measured by Self Perception Profile for Children, SPPC) and poorer attention when compared with controls. ${ }^{41}{ }^{42}$ Following two years' treatment with $\mathrm{GH}$ there was improved attention capacity and improved self-esteem such that with treatment there was no difference between cases and controls in scholastic competence, social acceptance, athletic competence, physical appearance, behavioural conduct, and general self-worth. ${ }^{41} 42$

\section{CONCLUSIONS}

On the present evidence from studies to final height GH therapy appears to be a safe and effective therapy in appropriate short SGA subjects. Short SGA children should first be investigated in order to identify causes of being born SGA and reasons for poor postnatal growth. Any specific cause found should be treated appropriately. In the child that then remains short or in whom no remediable cause has been identified, GH therapy may have a role to play in normalising height, and the earlier the child is identified the greater the potential response to treatment. The child must have clearly demonstrated that there has been no spontaneous catch-up growth. In other words there must be short stature (height SDS $<-2.5$ ), age 4 years or over, and height velocity below average. Determination of the GH status is not necessary but pretreatment IGF-I, IGF-BP3, fasting insulin, glucose, and lipids should be determined and blood pressure measured.

Treatment should be started after clinical assessment by a paediatric endocrinologist and can follow similar shared care guidelines currently used for other GH indications. The dose 
recommended in the new licence $(0.035 \mathrm{mg} / \mathrm{kg} /$ day $)$ appears to be adequate for the younger child but higher doses may give better results in the peri-pubertal patient. The response prediction model may allow refinement of the recommended dose in individual cases in the future. Continuous treatment is recommended and further research is needed to investigate whether intermittent treatment or different dose regimens may also be successful.

Detailed post-licensing surveillance should include long term follow up and careful metabolic monitoring supported by the pharmaceutical industry, as the implications of GH therapy on these subjects, at risk of the metabolic syndrome, will take many years to observe.

\section{Authors' affiliations}

L B Johnston, M O Savage, Paediatric Endocrine Section, Department of Endocrinology, William Harvey Research Institute, Barts and the London Queen Mary School of Medicine, London, UK

\section{REFERENCES}

1 Karlberg J, Albertsson-Wikland K. Growth in full-term small-for-gestationalage infants: from birth to final height. Pediatr Res 1995:38:733-9.

2 Lee PA, Chernausek SD, Hokken-Koelega AC, et al. International Small for Gestational Age Advisory Board consensus development conference statement: management of short children born small for gestational age, April 24-October 1, 2001. Pediatrics 2003;111(6 pt 1):1253-61.

3 Johnston LB, Clark AJ, Savage MO. Genetic factors contributing to birth weight. Arch Dis Child Fetal Neonatal Ed 2002;86:F2-3.

4 Hokken-Koelega AC, De Ridder MA, Lemmen RJ, et al. Children born smal for gestational age: do they catch up? Pediatr Res 1995;38:267-71

5 Gibson AT, Carney S, Cavazzoni E, et al. Neonatal and post-natal growth. Horm Res 2000;53(suppl 1):42-9.

6 Deiber M, Chatelain P, Naville D, et al. Functional hypersomatotropism in small for gestational age (SGA) newborn infants. J Clin Endocrinol Metab 1989:68:232-4.

7 Ackland FM, Stanhope R, Eyre C, et al. Physiological growth hormone secretion in children with short stature and intra-uterine growth retardation. Horm Res 1988;30:241-5.

8 Boguszewski M, Rosberg S, Albertsson-Wikland K. Spontaneous 24-hour growth hormone profiles in prepubertal small for gestational age children. J Clin Endocrinol Metab 1995;80:2599-606.

9 Giudice LC, de Zegher F, Gargosky SE, et al. Insulin-like growth factors and their binding proteins in the term and preterm human fetus and neonate with normal and extremes of intrauterine growth. $J$ Clin Endocrinol Metab 1995:80:1548-55.

10 Boguszewski $M$, Jansson C, Rosberg S, et al. Changes in serum insulin-like growth factor I (IGF-I) and IGF-binding protein-3 levels during growth hormone treatment in prepubertal short children born small for gestational age. J Clin Endocrinol Metab 1996;81:3902-8.

11 Rochiccioli $\mathbf{P}$, Tauber M, Moisan V, et al. Investigation of growth hormone secretion in patients with intrauterine growth retardation. Acta Paediatr Scand Suppl 1989;349:42-6

12 Sas T, de Waal W, Mulder P, et al. Growth hormone treatment in children with short stature born small for gestational age: 5-year results of a randomized, double-blind, dose-response trial. J Clin Endocrinol Metab 1999;84:3064-70.

13 Cianfarani S, Maiorana A, Geremia C, et al. Blood glucose concentrations are reduced in children born small for gestational age (SGA), and thyroidstimulating hormone levels are increased in SGA with blunted postnatal catchup growth. J Clin Endocrinol Metab 2003;88:2699-705.

14 Cianfarani S, Geremia C, Scott CD, et al. Growth, IGF system, and cortisol in children with intrauterine growth retardation: is catch-up growth affected by reprogramming of the hypothalamic-pituitary-adrenal axis? Pediatr Res 2002;51:94-9.

15 Boguszewski M, Albertsson-Wikland K, Aronsson S, et al. Growth hormone treatment of short children born small-for-gestational-age: the Nordic Multicentre Trial. Acta Paediatr 1998;87:257-63.

16 Van Pareren $Y$, Mulder $P$, Houdijk M, et al. Adult height after long-term, continuous growth hormone $(\mathrm{GH})$ treatment in short children born small for gestational age: results of a randomized, double-blind, dose-response GH trial. J Clin Endocrinol Metab 2003;88:3584-90.

17 Chatelain P, Job JC, Blanchard J, et al. Dose-dependent catch-up growth after 2 years of growth hormone treatment in intrauterine growth-retarded children. Belgian and French Pediatric Clinics and Sanofi-Choay (France). J Clin Endocrinol Metab 1994;78:1454-60.

18 Job JC, Chaussain JL, Job B, et al. Follow-up of three years of treatment with growth hormone and of one post-treatment year, in children with severe growth retardation of intrauterine onset. Pediatr Res 1996;39:354-9.
19 Chatelain P, de Zegher F. Growth hormone treatment in children with intrauterine growth retardation and Silver-Russell syndrome. Growth hormone therapy in KIGS - 10 years' experience. Johann Ambrosius Barth Verlag 1999:305-19.

20 de Zegher F, Maes M, Gargosky SE, et al. High-dose growth hormone treatment of short children born small for gestational age. J Clin Endocrinol Metab 1996;81:1887-92.

21 Ranke MB, Lindberg A. Growth hormone treatment of short children born small for gestational age or with Silver-Russell syndrome: results from KIGS (Kabi International Growth Study), including the first report on final height. Acta Paediatr Suppl 1996;417:18-26.

22 de Zegher F, Du Caju MV, Heinrichs C, et al. Early, discontinuous, high dose growth hormone treatment to normalize height and weight of short children born small for gestational age: results over 6 years. J Clin Endocrinol Metab 1999;84:1558-61.

23 Carel JC, Chatelain P, Rochiccioli P, et al. Improvement in adult height after growth hormone treatment in adolescents with short stature born small for gestational age: results of a randomized controlled study. J Clin Endocrinol Metab 2003;88:1587-93.

24 Zucchini S, Cacciari E, Balsamo A, et al. Final height of short subjects of low birth weight with and without growth hormone treatment. Arch Dis Child 2001;84:340-3.

25 Butenandt O, Lang $\mathrm{G}$. Recombinant human growth hormone in short children born small for gestational age. German Study Group. J Pediatr Endocrinol Metab 1997; 10:275-82.

26 Sas TC, Gerver WJ, De Bruin R, et al. Body proportions during 6 years of GH treatment in children with short stature born small for gestational age participating in a randomised, double-blind, dose-response trial. Clin Endocrinol (Oxf) 2000;53:675-81

27 Coutant $R$, Carel JC, Letrait $M$, et al. Short stature associated with intrauterine growth retardation: final height of untreated and growth hormone-treated children. J Clin Endocrinol Metab 1998;83:1070-4.

28 Ranke MB, Lindberg A, Cowell CT, et al. Prediction of response to growth hormone treatment in short children born small for gestational age: analysis of data from KIGS (Pharmacia International Growth Database). J Clin Endocrinol Metab 2003;88:125-31

29 de Zegher F, Butenandt $O$, Chatelain $P$, et al. Growth hormone treatment of short children born small for gestational age: reappraisal of the rate of bone maturation over 2 years and metanalysis of height gain over 4 years. Acta Paediatr Suppl 1997;423:207-12.

30 Sas T, Mulder P, Hokken-Koelega A. Body composition, blood pressure, and lipid metabolism before and during long-term growth hormone $(G H)$ treatment in children with short stature born small for gestational age either with or without GH deficiency. J Clin Endocrinol Metab 2000;85:3786-92.

31 Leger J, Garel C, Fjellestad-Paulsen A, et al. Human growth hormone treatment of short-stature children born small for gestational age: effect on muscle and adipose tissue mass during a 3-year treatment period and after 1 year's withdrawal. J Clin Endocrinol Metab 1998;83:3512-16.

32 Swerdlow AJ, Higgins CD, Adlard P, et al. Risk of cancer in patients treated with human pituitary growth hormone in the UK, 1959-85: a cohort study. Lancet 2002;360:273-7.

33 Barker DJ, Gluckman PD, Godfrey KM, et al. Fetal nutrition and cardiovascular disease in adult life. Lancet 1993;341:938-41.

34 Leger J, Levy-Marchal C, Bloch J, et al. Reduced final height and indications for insulin resistance in 20 year olds born small for gestational age: regional cohort study. BMJ 1997;315:341-7.

35 Yajnik CS, Fall CH, Vaidya U, et al. Fetal growth and glucose and insulin metabolism in four-year-old Indian children. Diabet Med 1995; 12:330-6.

36 Van Pareren Y, Mulder P, Houdijk M, et al. Effect of discontinuation of growth hormone treatment on risk factors for cardiovascular disease in adolescents born small for gestational age. J Clin Endocrinol Metab 2003;88:347-53.

37 Soto N, Bazaes RA, Pena V et al. Insulin sensitivity and secretion are related to catch-up growth in small-for-gestational-age infants at age 1 year: results from a prospective cohort. J Clin Endocrinol Metab 2003;88:3645-50.

38 de Zegher F, Ong K, van Helvoirt M, et al. High-dose growth hormone (GH) treatment in non-GH-deficient children born small for gestational age induces growth responses related to pretreatment $\mathrm{GH}$ secretion and associated with a reversible decrease in insulin sensitivity. $J$ Clin Endocrinol Metab 2002;87:148-51

39 Cutfield WS, Jackson WE, Jefferies $C$, et al. Reduced insulin sensitivity during growth hormone therapy for short children born small for gestational age. J Pediatr 2003;142:113-16.

40 O'Keeffe MJ, O'Callaghan $M$, et al. Learning, cognitive, and attentional problems in adolescents born small for gestational age. Pediatrics 2003;112:301-7.

41 van der Reijden-Lakeman I, Slijper FM, Dongen-Melman JE, et al. Selfconcept before and after two years of growth hormone treatment in intrauterine growth-retarded children. Horm Res 1996:46:88-94.

42 van der Reijden-Lakeman IE, de Sonneville LM, Swaab-Barneveld HJ, et al. Evaluation of attention before and after 2 years of growth hormone treatment in intrauterine growth retarded children. J Clin Exp Neuropsychol 1997; 19:101-18. 